\title{
Pleomorphic Adenoma of Lacrimal Gland: A Rare Entity
}

\section{Kirti Chadha Kazi ${ }^{1}$, Vivek Choodamani Parameshwar ${ }^{1 *}$, Vikas S Kavishwar ${ }^{1}$ and Prithesh Bhaskar Shetty ${ }^{2}$}

${ }^{1}$ Department of Histopathology, Global Reference Laboratory (GRL), Metropolis Healthcare limited, Kohinoor City, Commercial I, A Wing, 4th Floor, Kirol road, Off LBS Marg, Opp. Holy Cross School, Kurla (W), Mumbai- 400070, Maharashtra, India. ${ }^{2}$ Department of Ophthalmology, Khan Bahadur Haji Bachooali Ophthalmic Hospital, Jehangir Merwanji road, Parel, Mumbai- 400012, Maharashtra, India.

\section{ABSTRACT}

Among the various tumours affecting the lacrimal gland, pleomorphic adenomas though most common can present clinically and radiologically as worrisome tumours. Histopathologic diagnosis hence is very critical for these tumours. We present a case of pleomorphic adenoma of the lacrimal gland which we encountered at our institutes. The patient was a 46-year-old male who came with complaints of a gradually progressing swelling in the right eye not associated with much pain or significant loss of vision. MRI revealed a large lobulated extrachoanal mass causing mass effect and scalloping of the adjacent bony structures. An excision biopsy was done and sent for histopathological examination. Histologically the tumour showed a biphasic morphology comprising of epithelial (ductal and myoepithelial) and chondromyxoid stromal components. Immunohistochemistry showed positivity for pan CK and CK 7 in ductal epithelial cells, p63 and S100 in myoepithelial cells and a low Ki67 index. On the basis of immunohistochemistry profile along with clinicoradiological correlation a final diagnosis of pleomorphic adenoma of the lacrimal gland was made. The patient post-surgery was doing well but was lost to follow up. It can thus be seen that is it absolutely necessary to accurately diagnose these benign but clinically misconceiving rare tumours of the lacrimal gland for appropriate management of such patients.

Keywords: Lacrimal Apparatus; Adenoma, Pleomorphic; Benign

\section{Introduction}

Lacrimal gland tumours are relatively rare in clinical practice. ${ }^{[1,2]}$ Among these, pleomorphic adenomas are the most common. ${ }^{[3]}$ These are generally slow-growing, well-circumscribed tumours that resemble their salivary gland counterpart both histologically and prognostically. ${ }^{[4]}$ However, because of the relatively sensitive site of the lacrimal gland, their presentation can be clinically alarming. Yet prognosis in terms of vision and long-term survival after complete surgical excision is excellent. Recurrence due to incomplete surgical excision and malignant transformation to carcinoma ex pleomorphic adenoma is known to occur but rare. ${ }^{[4]}$ Taking all these points into consideration it can be seen that accurate diagnosis of these tumours is of prime importance for the patient. We discuss here a case of lacrimal gland pleomorphic adenoma which we encountered at our institute.

\section{Case Report}

The patient was a 46-year-old male, resident of Mumbai and was a salesman by occupation. He had noticed a small swelling in the upper outer part of the right eye 1-2 years back but had ignored it due to lack of any problems. The swelling gradually increased in size and began to have a diffuse involvement. Since the last 5-6 months it assumed a considerable size and was leading to "popping out" of the right eyeball (Figure 1a). The patient also now had complaints of excessive watering of the eyes, mild blurring of vision and mild pain in the right eye in addition to cosmetic problems. On examination the ophthalmologist decided to go ahead with an MRI to determine the exact origin and extent of the lesion. MRI showed a $3.8 \times 3.3 \times 2.7 \mathrm{~cm}$ sized lobulated heterogeneous lesion in the superior extrachoanal space, not clearly seen separately from the lacrimal gland. It was causing scalloping of orbital roof, severe proptosis and also mass effect on the optic nerve (Figure 2). The differentials suggested were a malignant lacrimal gland tumour, lymphoma of lacrimal gland, soft tissue sarcoma or a primary cartilage/bone tumour. An excision biopsy was performed and the sample was sent for histopathological examination. Multiple greyish white soft tissue bits were received aggregating to $6.5 \times 5.5 \times 4.5 \mathrm{cms}$ indicating there was rupture of the capsule. On histopathological examination sections showed a biphasic tumour composed of epithelial (ductal, myoepithelial) and chondromyxoid stromal components. Ductal components were in the form of nests, tubules, cysts and cords. Myoepithelial cells lined the outer layer of tubules and cysts and had an oval to spindle-shaped morphology. Background showed 
typical chondromyxoid stroma with areas of hyalinisation (Figure 3). No atypia, mitosis or necrosis were seen. On immunohistochemistry the ductal epithelial cells were positive for pan CK and CK7. The myoepithelial cells were positive for p63 and S100. Ki67 index was low (Figure 4). On the basis of these findings, a final immunohistological diagnosis of pleomorphic adenoma of lacrimal gland origin was given. The patient had complete relief of symptoms post op at the time of discharge (Figure 1b). Further plan of management was a repeat MRI after 3 months to check for any residual lesion. However, after discharge the patient was lost to follow up.

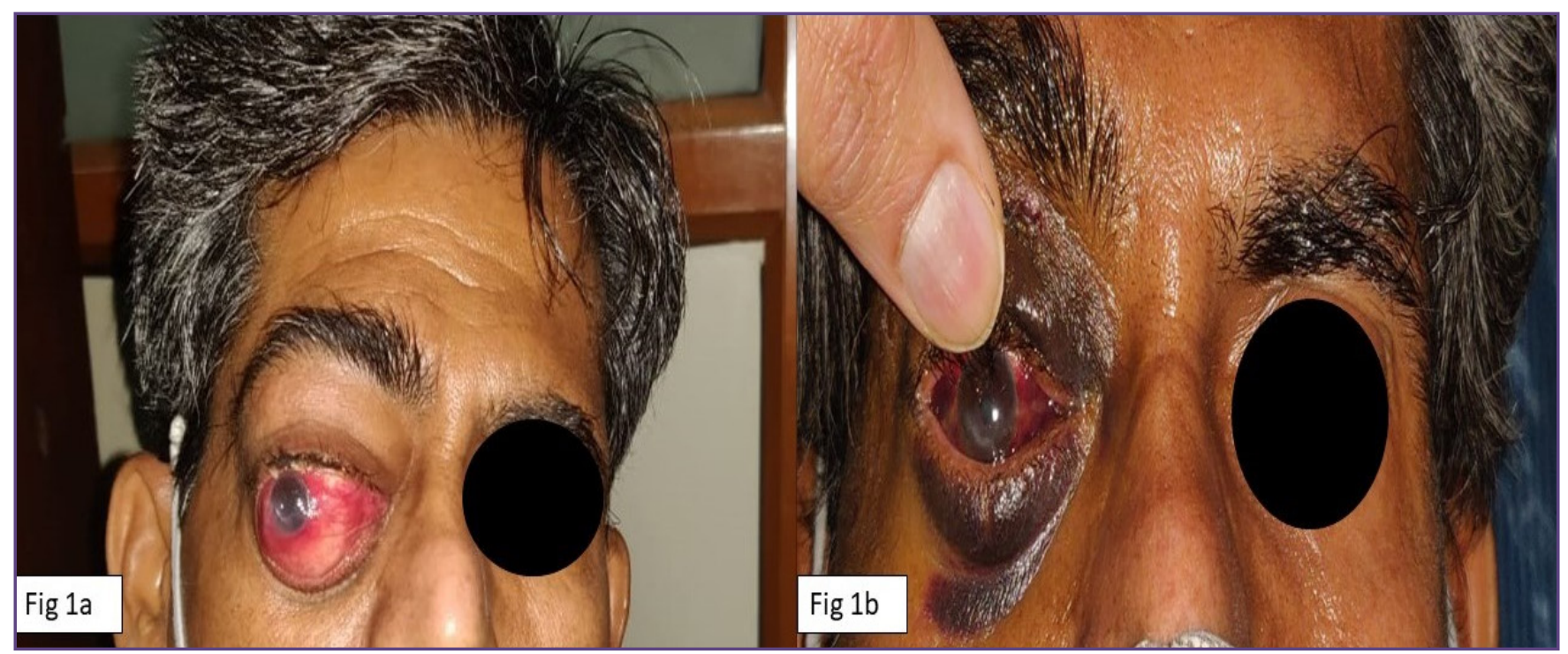

Fig. 1: a) Downward and medial displacement of the eyeball leading to "popping out" of eyeball. b) Post-operative resolution of the lesion.

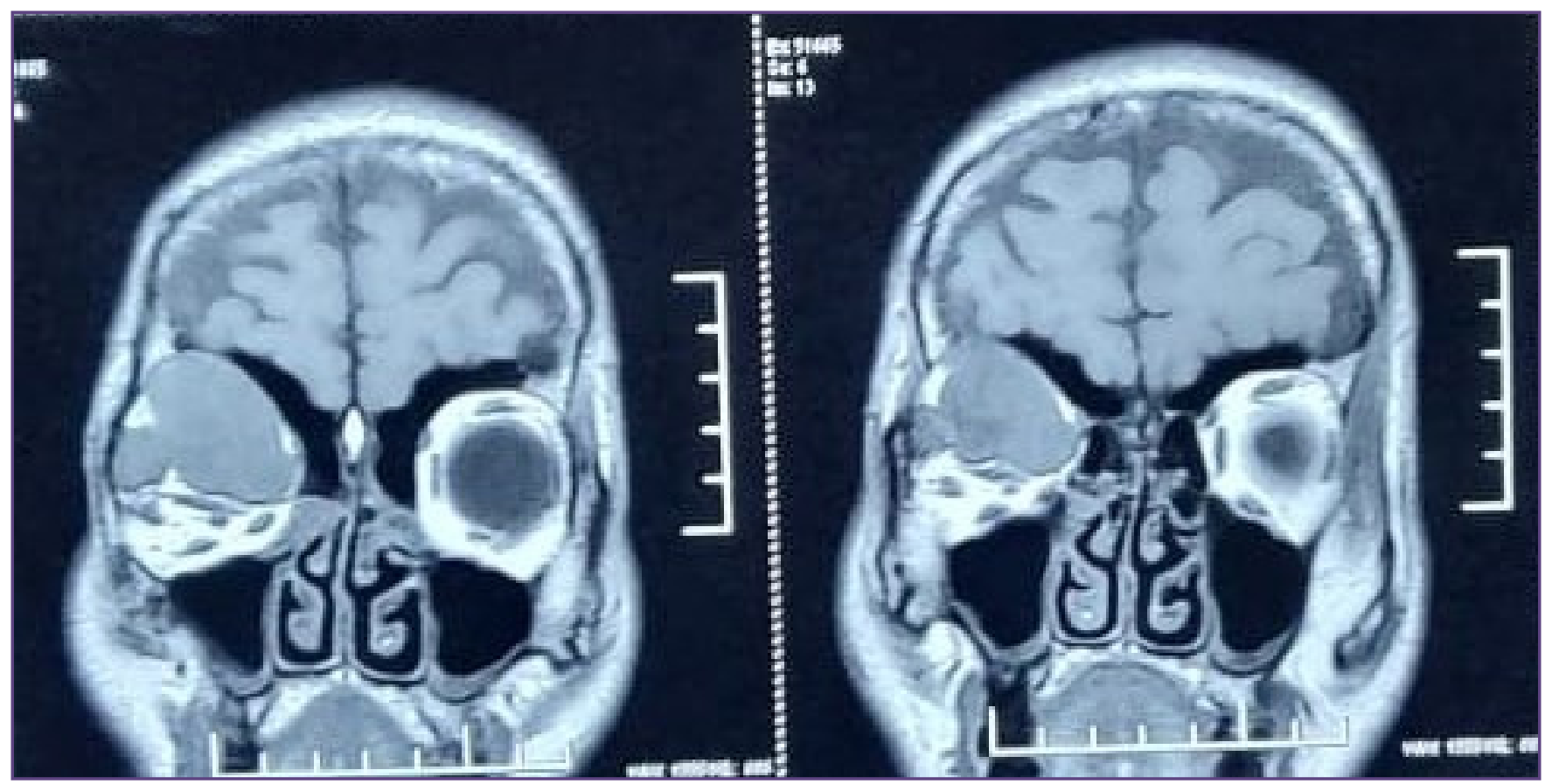

Fig. 2: MRI: Lobulated heterogeneous lesion in the superior extrachoanal space not clearly seen separately from the lacrimal gland causing scalloping of orbital roof, severe proptosis and also mass effect on the optic nerve. 


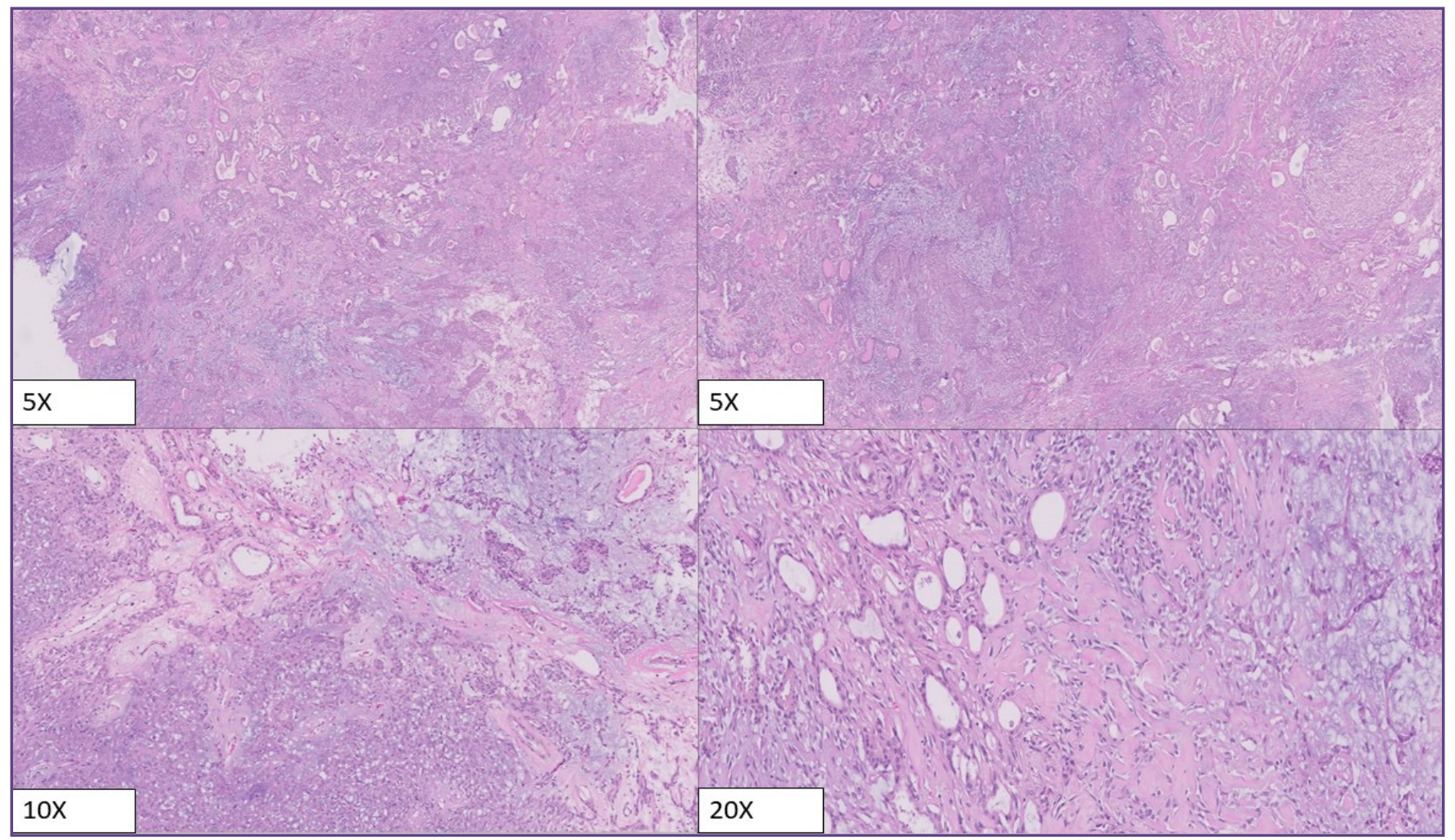

Fig. 3: H\&E (5X, 10X \& 20X) - Showing the characteristic biphasic morphology comprising ductal \& myoepithelial cells in a chondromyxoid stromal background.

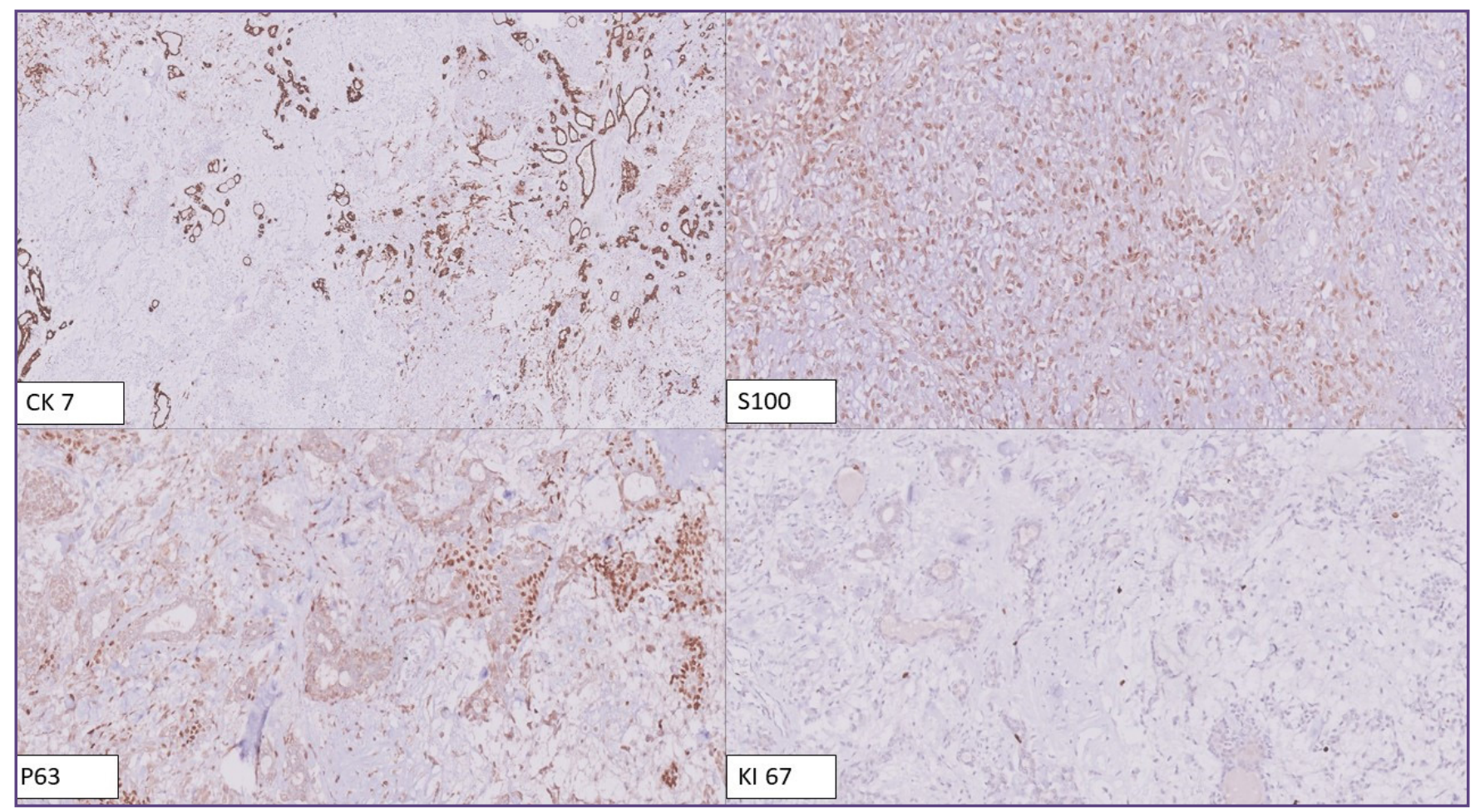

Fig. 4: IHC Profile: CK 7 highlights the inner ductal epithelial cells, S100 \& p63 the outer myoepithelial cells. Ki67: Low index. 


\section{Discussion}

The lacrimal gland is a bilobed, eccrine gland in the lacrimal fossa located in the superolateral part of each orbit. Its secretion lubricates and provides nutrients for the eye and contains the bactericidal enzyme lysozyme. ${ }^{[5]}$ Tumours of the lacrimal gland are rare in clinical practice and constitute about $7-9 \%$ of all orbital tumours. ${ }^{[1,2]}$ The most common among these is pleomorphic adenoma (PA). [6] Orbital lobe of the lacrimal gland is most commonly involved ${ }^{(4)}$. They most commonly affect people in the $3 \mathrm{rd}$ and 4th decades of life like in the present case. However, there is no clear gender predominance. ${ }^{[7]}$

The clinical presentation is usually a slowing growing painless palpable mass in the upper outer quadrant of the orbit with inferonasal displacement of the globe. ${ }^{[1,2,8,9]}$ They can also have epiphora, increase in intraocular pressure, visual impairment and diplopia. ${ }^{[2,3,8,9]}$ Some of these features were seen in the present case. Malignancy is suspected when there is a rapid onset of symptoms, pain, and bony destruction on radiology. ${ }^{[10]}$ Diagnostic imaging is critical for lacrimal gland neoplasms. ${ }^{[4]}$ On MRI, pleomorphic adenomas generally are isointense lesions with regular margins. ${ }^{[7]}$ However, certain radiographic findings like slightly irregular circumscription of the lesion, mild bone erosion, and calcifications may sometimes be misinterpreted as features of other malignant tumours of lacrimal gland, lymphomas and rarely soft tissue or bone tumours.$^{[3,11]}$ This is a drawback which can be seen in PA in this region raising the possibility of a clinico radiologic misdiagnosis.

The definitive diagnosis however is based on the histopathological examination. ${ }^{[7]}$ Incisional or needle core biopsies are however contraindicated due to chances of spillage and seeding of the tumour and complete excisional biopsy is advised..$^{[4]}$ Histologically, PAs can have a wide range of histomorphologies with varying proportions of epithelial and mesenchymal stromal components. The epithelial component comprises of double-layer ductal structures, acini, tubules, strands and sheets of cells with inner ductal and surrounding myoepithelial cells. They are dispersed within a characteristic background of loose chondromyxoid tissue and rarely foci of bone. In most cases there is no evidence of dysplasia or increased mitotic activity. ${ }^{[4]}$ Immunohistochemical profile is unique and demonstrates a different profile for each component. The ductal epithelial cells are positive for pan CK and CK7. The myoepithelial cells are positive for p63, S100, SMA, CD10 and other myoepithelial markers. Vimentin is positive in the chondromyxoid stromal elements. Ki67 index is low. On the basis of this characteristic immunohisto profile, a diagnosis of pleomorphic adenoma was reached in the present case.

Differential diagnosis varies from benign lesions like chronic dacryoadenitis, Sjogren's syndrome, sarcoidosis, benign lymphoid hyperplasia, intralacrimal schwannoma and hemangiopericytoma to malignant lesions like adenoid cystic carcinoma, mucoepidermoid carcinoma, malignant soft tissue and bone tumours. ${ }^{[7]}$ Radiology helps in most cases but histopathological examination can easily and accurately distinguish between each of these entities. ${ }^{[12]}$

Malignant transformation though rare is known to occur in pleomorphic adenomas. The incidence of malignant transformation increases with duration of tumor and it accounts for around $10 \%$ of all malignant tumours of lacrimal gland. ${ }^{[3,13]}$ Out of these $75 \%$ of the cases are mucoepidermoid carcinoma, adenoid cystic carcinoma, salivary duct carcinoma, and adenocarcinoma not otherwise specified (NOS). ${ }^{[13]}$

Molecular studies on PAs of salivary glands showed that the development of Carcinoma Ex- Pleomorphic adenoma follows a multi-step model of carcinogenesis. It is associated with progressive loss of heterozygosity at $8 \mathrm{q}$, $12 \mathrm{q}$, and finally $17 \mathrm{p} .{ }^{[13]}$ The PLAG1 gene translocation $\mathrm{t}$ $(5 ; 8)(\mathrm{p} 13 ; \mathrm{q} 12)$ is highly specific for PAs. It can hence be used as a potential powerful diagnostic marker. ${ }^{[4]}$ Findings have shown that lacrimal gland PAs have similar genetic profiles to salivary PAS making all the diagnostics and etiopathological findings useful in understanding and diagnosing the lacrimal counterparts.

Treatment is usually in the form of surgical intervention. A lateral orbitotomy with complete resection with an intact capsule is the surgery of choice. ${ }^{[3,4]}$ Lateral orbitotomy involves a horizontal skin incision from the lateral canthal angle, followed by subcutaneous tissue dissection, incision of the periosteum and its elevation, dissection of temporalis fascia and muscle and finally removal of the lateral orbital bony rim to gain access to the extrchoanal space from where the required excision or biopsy can be performed as was in the present case. ${ }^{[14]}$ Incomplete capsule removal or defects in the capsule can cause displacement of the myxoid component of PA into the orbital cavity or incomplete resection of the tumour leading to recurrence. Radiotherapy, may be considered for rare inoperable cases or for recurrent or residual tumours. ${ }^{[4]}$ There is however a potential threat for recurrence and hence makes diagnosis of these entities all the more important since they have a good outcome even if they recur and can be subsequently tackled appropriately. Follow up in most of these cases of PA is at 3 months and at 1-year post-op to check for recurrence of these tumours. 


\section{Conclusion}

Pleomorphic adenomas though rare, are the most common tumours of the lacrimal gland. These are benign tumours but can clinically and radiologically mimic and instead be misdiagnosed as other malignant tumours. Histopathologic examination is the gold standard for diagnosis and these tumours can be easily be diagnosed on the basis of their characteristic immunohistochemical profile. Accurate diagnosis helps in proper management, close follow up for recurrence, timely treatment and excellent prognosis and long-term survival in these benign but uncommon tumours of the lacrimal gland.

\section{Acknowledgements}

None

\section{Funding}

None

\section{Competing Interests}

None Declared

\section{Ethics Statement Including Patient Consent:}

A written informed consent from the patient himself was taken for use of his images for medical, scientific or educational purposes. The study was conducted according to the principles of the Declaration of Helsinki.

\section{References}

1. Santos RR, Damasceno RW, de Pontes FS, Cursino SR, Nishiwaki Dantas MC, Vital Filho J, et al. Ten-year followup of a case series of primary epithelial neoplasms of the lacrimal gland: clinical features, surgical treatment and histopathological findings. Arq Bras Oftalmol. 2010; 73(1):33-9.

2. Halli RC, Mishra S, Kini YK, Kharkar VR, Hebbale MA. Modified lateral orbitotomy approach: a novel technique in the management of lacrimal gland tumors. J Craniofac Surg. 2011; 22(3): 1035-8.
3. Chandrasekhar J, Farr DR, Whear NM. Pleomorphic adenoma of the lacrimal gland: case report. Br J Oral Maxillofac Surg. 2001; 39(5):390-3.

4. William Harrison, Patricia Pittman et.al. Pleomorphic adenoma of the lacrimal gland: A review with updates on malignant transformation and molecular genetics. Saudi Journal of ophthalmology (2018) 32, 13-16.

5. Antony J, Gopalan V, Smith RA, Lam AK. Carcinoma ex pleomorphic adenoma: a comprehensive review of clinical, pathological and molecular data. Head Neck Pathol 2012; 6(1):1-9.

6. Binatli Özcan, Onur Yaman, Nail Özdemir, Isın Gökçöl Erdog an. Pleomorphic adenoma of lacrimal gland. J Surg Case Rep 2013;13 (10):rjt089.

7. Iyeyasu J, Reis F, Altemani A, Monteiro de Carvalho K. An unusual presentation of lacrimal gland pleomorphic adenoma. Rev Bras Oftalmol 2013;72(5):338-40.

8. Friedhofer H, Mendonça FP, Salles AG, Ferreira MC. Adenoma pleomórfico de glândula lacrimal - Relato de caso. Rev Soc Bras Cir Plast. 1997;12(3):69-74

9. Gupta S, Garg S, Singh S, Hasija S, Chaudhary M. Pleomorphic adenoma of lacrimal gland in a 5-year-old child: Diagnosed on aspiration cytology. Diagn Cytopathol. 2013;41(6):565-6.

10. Gündüz K, Shields CL, Günalp I, Shields JA. Magnetic resonance imaging of unilateral lacrimal gland lesions. Graefes Arch Clin Exp Ophthalmol. 2003;241(11):907-13.

11. Currie ZI, Rose GE. Long-term risk of recurrence after intact excision of pleomorphic adenomas of the lacrimal gland. Arch Ophthalmol 2007;125(12):1643-6.

12. Agrawal S, Gupta S, Das D et al (2021, June 1). Imaging in Oculoplasty and Orbit. Retrieved from https://eyewiki.org/ Imaging_in_Orbit_and_Oculoplasty.

13. Shields JA, Shields CL. Malignant transformation of presumed pleomorphic adenoma of lacrimal gland after 60 years. Arch Ophthalmol 1987;105(10):1403-5.

14. Das D, Modaboyina S, Gupta S et al. Surgical approaches to the orbit - The past and the present. IP Int J Ocul Oncol Oculoplasty $2021 ; 7(1): 5-11$.

*Corresponding author:

Dr. Vivek Choodamani Parameshwar, B-17, Prabhu Kripa CHS, Nariman Road, Vile Parle (East), Mumbai- 400057.

Phone: +91 9930591749

Email: choodamani.parameshwar@gmail.com

Date of Submission $\quad: 17 / 05 / 2021$

Date of Final Revision : 20/06/2021

Date of Acceptance $\quad: 28 / 06 / 2021$

Financial or other Competing Interests: None.

Date of Publication $\quad: 30 / 07 / 2021$ 